\title{
IDÉIAS
}

\section{Faltam partidos para nosso parlamentarismo}

Jarbas Passarinho

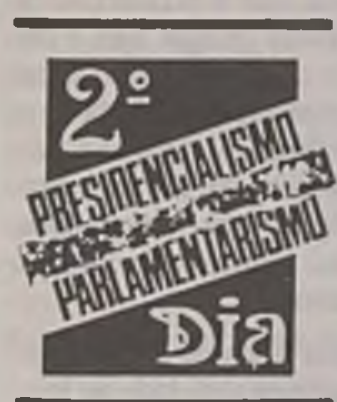

"Do Prof. James Young, nós tiramos a conclusão da apresentação de um regime presidencialista com forte Legislativo. Talvez um dos raros exemplos de um forte Legislativo hoje no mundo, diante de um regime presidencialista.

E, especialmente, uma vocação admirável de fidelidade aos postulados constitucionais. $\hat{E}$ um caso, portanto, em que eu diria, em termos muito usados, hoje, no Brasil, é um caso atípico a ser considerado.

Do Prof. e Ministro Nascimento Silva, com o qual eu desde logo fico de acordo, nós ouvimos uma preleção a respeito dos dois tipos de regime e de forma de governo, e ele se definindo pelo presidencialismo. E, do Professor João Gilberto, exatamente o contrário.

Ora, o Dr. João Gilberto colocou um problema aqui que me parece de grande importância, e que eu vejo colocado pela primeira vez. Diz ele que, parlamentarismo ou presidencialismo, o que nós devemos primeiro considerar é um problema básico, ou seja, quando se compara a capacidade de trabalho entre o Executivo e o Legislativo, vêse que o Executivo, de um modo geral, no regime presidencialista, se preparou bem mais dinamicamente para o exercício do poder do que o Legislativo para fazer o seu papel, o que acabou transformando o Legislativo em grande fórum de debates, em caixa de ressonâncias de problemas nacionais, mas dando ao Executivo, como salientou o Ministro Nascimento e Silva, mais força,

Jarbas Passarinho é Senador pelo PDS do Pará. Debatedor do 2 : Dia

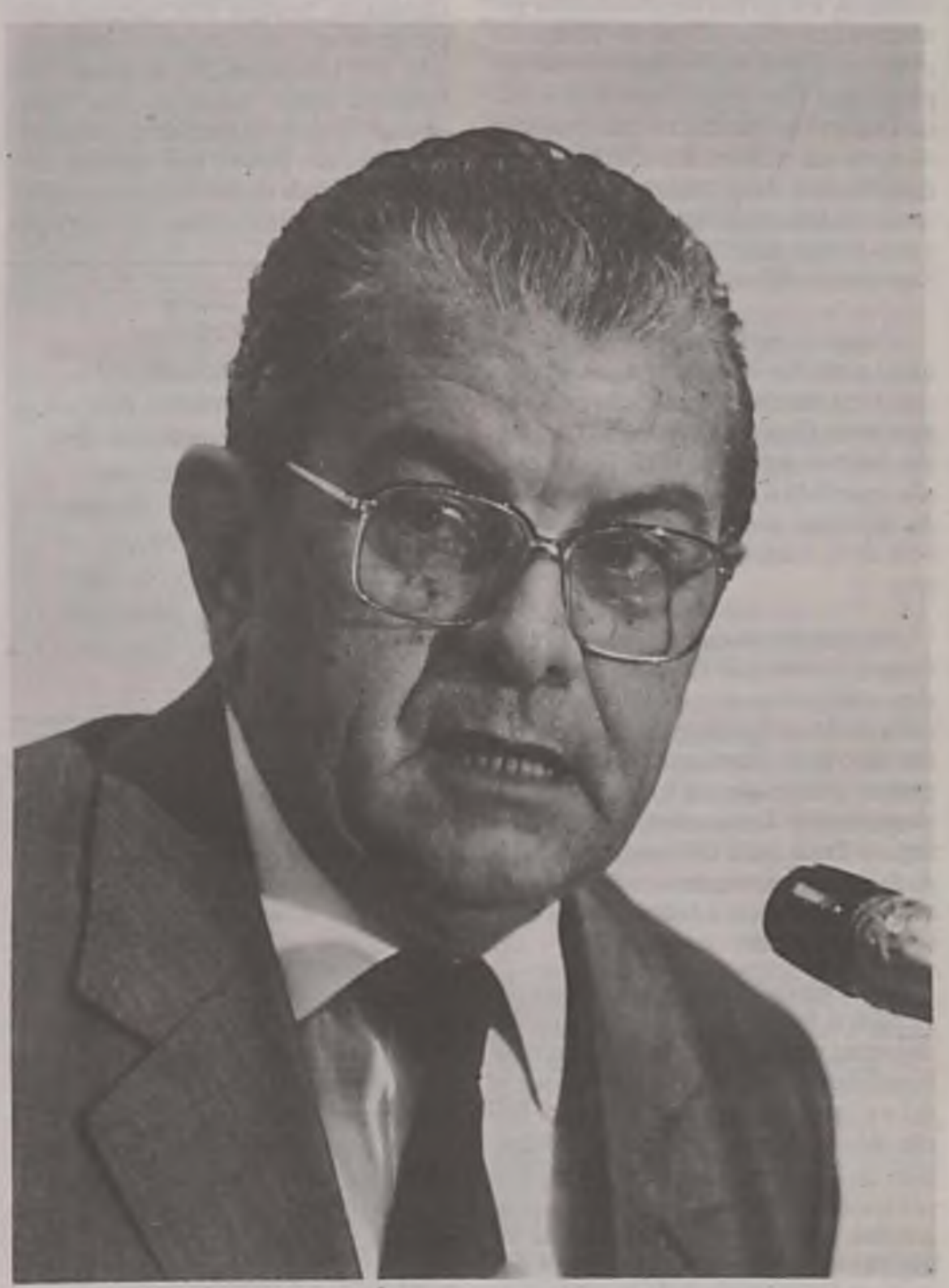

mais habilidade, mais capacidade para gerir a coisa pública.

O ponto fundamental aqui no Brasil, quando se discute presidencialismo e parlamentarismo, é que ele é conjuntural. Não se discute por convicção; na maioria dos casos, discute-se por conveniência. Nós tivemos um arremedo de parlamentarismo aqui em 1961 exatamente para proporcionar ao VicePresidente da República poder assumir o poder depois de uma renúncia do Pre- 


\section{IDÉIAS}

sidente efetivo, que era o Sr. Jânio Quadros. E vimos desde logo que não funcionou, não funcionou porque nunca foi parlamentarista. Eu diria que se eu sou presidencialista é porque sou parlamentarista. E ai explicaria não um jogo de palavras. Como admito que a for-ma fundamental ou a característica mais brilhante para nós do parlamentarismo é esta salientada pelo Dr. João Gilberto, é a forma de administrar pacificamente os conflitos do poder, do poder que está sendo mantido ou do poder que está sendo disputado e evitar que isso se traduza em intervençōes de natureza militar. Para termos uma possibilidade desta natureza, seriam necessários pré-requisitos que não temos, e que foram salientados pelo Ministro Nascimento Silva.

Primeiro: partidos sólidos, tradicionais, partidos que não desapareçam com uma derrota eleitoral. Eu fui líder, aqui nesta Casa, de 41 senadores, na antiga Arena e depois no PDS. Feita a eleição e perdida a eleição pelo meu partido, a eleição presidencial, eu hoje sou lider de 5 , inclusive eu mesmo, dos 41 para cá.

No meu Estado, por exemplo, terminamos uma eleição fazendo 19 deputados estaduais contra 20 deputados estaduais da coligação que nos venceu. Ao cabo de poucos anos de governo, os nossos 19 eram apenas 9 . E o poder secciona através dessas ofertas a que se referiu o Prof. João Gilberto, da capacidade de influenciar, seja ela fardada, civil ou eclesiástica, e com isso não existe partido sólido.

Dizia agora há pouca, sussurrava para mim o Prof. João Gilberto, que um dos erros de 64 foi ter climinado o multipartidarismo. É uma discussão que se faz e a cada dia se torna mais atual. Então nós não temos partidos sólidos. Não diria que não temos partidos sem programas. Temos partidos com programas. Eu mesmo me orgulho de ter um partido considerado como um dos melhores programas de partidos de quadro do Brasil. E temos partidos ideológicos que têm programas também. Aí surge desde logo um problema para nós. Como evitar que parlamentarismo os partidos se fraccionem de tal modo que geram inúmeras siglas, mui-

tas delas servindo apenas para oportunismo político, negociação política, e não para negociação doutrinária ou ideológica?

Se nós usarmos a sistemática alemã, que dá $5 \%$, por exemplo, para a votação nacional, quem não tiver os $5 \%$ não teria partido reconhecido, nós teríamos aqui no Brasil, na circunstância atual, a eliminação dos partidos de base ideológica, porque eles não têm essa percentagem, por enquanto pelo menos. Em compensação, deixando que funcione como funciona, nós temos uma infinidade de partidos, ao contrário de outros países, que também têm uma infinidade de partidos nas eleições, mas que se transformam em partidos

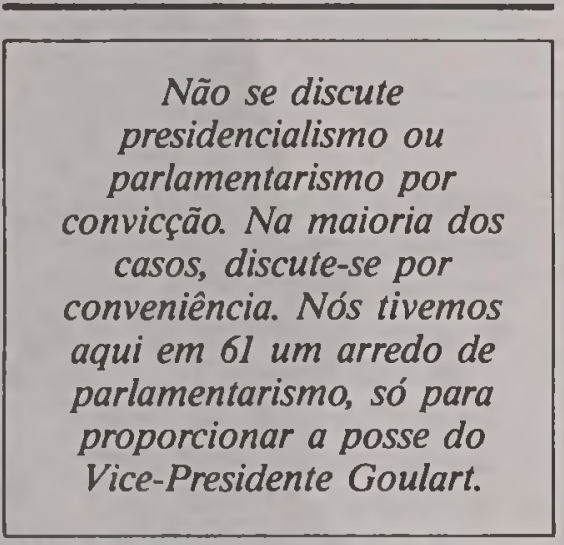

quase no bipartidarismo americano praticamente, no sistema inglês, no sistema alemão, onde dois ou três partidos são os partidos dominantes, o resto aparece no momento em que a eleição se faz.

Mas, mais importante ainda do que a falta de solidez dos partidos políticos para justificar um parlamentarismo no Brasil, eu considero exatamente o que percutido aqui duplamente pelo Min. Nascimento Silva e pelo Dr. João Gilberto, que é o problema da burocracia, com uma ligeira discrepância do ponto de vista do Dr. João Gilberto que, quando achou que a burocracia não poderia ter talvez o papel que foi a ela atribuído pelo Ministro Nascimento e Silva. Ora, nós temos uma burocracia instável, altamente vulnerável à mudança dos Ministros. Sem ofensa a nenhum deles, aqui está um ministro atual, dois ou três ministros aqui, sem ofensa a nenhum de nós, quando o ministro che- ga ao poder, devido a essa circunstância lembrada pelo prof. João Gilberto, do número enorme de funções de confiança, então quem era da confiança do Ministro do Interior passa a não ser da confiança do novo Ministro e a conseqüência disso é que se demite do Secretário-Geral ao ascensorista e ao servente que serve o café. Então a mudança é geral. E como pensar numa estabilidade política, que é característica do parlamentarismo latino? não é do parlamentarismo anglo-saxônico, mas é do parlamentarismo latino. Veja-se a Espanha, veja-se Portugal, veja-se a Itália, sobretudo. Veja-se a França, comparada com a Inglaterra, comparada com a Alemanha, comparada com os paises escandinavos.

Nós temos dois tipos de comportamento, dois tipos de estabilidade ou instabilidade funcional. Eu dou um exemplo. Eu tive a honra de suceder o $\mathrm{Mi}$ nistro Nascimento Silva na pasta do Trabalho e Previdência Social, em 1967. Em 1968 nós tínhamos um projeto a ser feito com a Itália, ainda iniciado na administração do Ministro Nascimento Silva, para fazermos um acordo bilateral na Previdência Social. E, não querendo fazer duas viagens, eu deixei para fazer em junho a viagem, porque em junho obrigatoriamente eu iria à Conferência da Organização Internacional do Trabalho. Então cheguei a Roma uma semana antes da minha presença, que eu entendi como necessária, na Conferência de Genebra. Recebido no aeroporto pelo Embaixador brasileiro e pelo correspondente italiano, me dizia o Embaixador brasileiro: "o governo caiu esta tarde". Era à noite que eu estava viajando. $\mathrm{E}$ eu, acostumado com o governo que cai no Brasil, disse imediatamente ao Embaixador: "nesse caso eu vou embora para a Suiça". Ele disse: "não, senhor; o senhor vai discutir com os burocratas". Que burocratas? Burocratas para mim era quase um palavrão. Que burocratas? Não. O senhor vai discutir com os burocratas italianos. Por que? Porque os burocratas de lá, a exemplo da excepcional burocracia francesa da ENA, o burocrata da Itália também é aquilo que o Ministro Aluizio Alves está querendo fazer, justamente, uma burocracia por carreira: carreira definida, ascensão funcional por concurso, enfim, o mérito. Concur- 


\section{IDÉIAS}

so, eu afirmo, nem sempre é o melhor, mas de qualquer maneira é melhor do que qualquer outro sistema de apadrinhamento.

Discuti, com o correspondente ao Secretário-Geral, fui embora para Genebra, participei da conferência e voltei ao Brasil. No Brasil, o novo governo italiano já tinha ratificado o acordo bilateral que o Brasil ainda não tinha feito. Agora, eu imagino aqui no Brasil, diante destas circunstâncias, a sucessão de governos, o que aconteceria com os funcionários? Eu não me vou referir nem aos apartamentos funcionais com que o Ministro Aluizio Alves está preocupado, mas com os funcionários da Casa. Então, este para mim é um problema sério.

A grande questão fundamental que me parece hoje tem dois campos. Permanente, a preocupação com a questão militar. Esta é a preocupação permanente dos parlamentaristas, e eu lhes dou razão, eu acho justa aquela colocação do Prof. João Gilberto, a administração pacífica dos conflitos. Mas não terá sido um engano admitir que, durante cinqüenta anos de parlamentarismo, no Império, nós tivemos tranqüilidade? Vive-se a dizer isso ai. A mim me parece uma falácia. Só houve tranqüilidade politica exatamente na medida em que nós tivemos sucessivas dissoluçōes de parlamentos. Várias crises políticas, uma seguindo a outra. É verdade que tivemos também guerrilhas internas, não diria que tivemos guerra de secessão mas tivemos guerras prolongadas e duras, mas de qualquer maneira se resolveu o problema pacificamente através dos gabinetes que se sucediam. Mas o melhor general brasileiro, na hora em que nós enfrentávamos o ditador do Paraguai, numa aliança ArgentinaBrasil-Uruguai, o melhor general brasileiro foi colocado de escanteio, como se diria em linguagem brasileira de futebol, foi colocado na reserva para não ocupar justamente a chefia dos exércitos porque não era um participante do governo partidário, daquele partido que, no momento, dominava o governo. E, mais, quando apareceu a questão militar - e eu vou dizer isto na presença de um historiador como Luiz Viana Filho - o que caiu não foi mais o governo, foi o regime Caiu foi o Im- pério, e se fez a República. De maneira que se colocar um dispositivo antigolpe é esquecer de uma coisa que me parece fundamental, e que, dada minha origem, eu reivindico poder dizer. A minha origem é castrense, a minha origem é militar, eu passei 29 anos na vida militar para depois passar na vida

politica desde 64 para cá. Há um extraordinário componente do golpe militar que fazem questão, os civis, de esconder: é o componente civil do golpismo. Os militares são procurados pelos políticos, são buscados nos seus quartéis, quando os políticos dizem que a eleição foi fraudada, que o Presidente da República chegou ao poder por uma eleição fraudada, ou violentada pela influência do poder econômico, ou por esta, ou por aquela razāo.

Não existe dentro da força armada uma idéia golpista em si, latente e permanente para assumir como quem quer apenas dominar o poder. Existe, isto sim, uma classe média armada, que é altamente contaminável pelas açōes politicas. É, a partir destas ações políticas, automaticamente quem detém as armas; os civis quando se revoltam vão às urnas e derrubam o governo; se for o caso, os militares acabam com as armas nas mãos, derrubando o governo.

Então, para nós, o problema seria, para termos tranqüilidade, seria preciso que nós primeiro pensássemos na organização partidária, na organização burocrática, para podermos ter um parlamentarismo de fato, que se respeita a si próprio. E, mais ainda, o golpismo desaparecerá na medida em que justamente a sociedade se tornar complexa. Na medida em que ela se tornar complexa, envelhecer-se, amadurecer, tiver uma maturidade maior, são aí os exemplos dos paises europeus. A França no século passado teve 14 Constituiçōes diferentes. E não se dirá que ela foi totalmente imune, como disse muito bem - Ministro Nascimento e Silva na sua conferência à própria questão militar.

Mas esta França hoje tem estabilidade relativa. A partir de quê? A partir de uma correção de um parlamentarismo de tipo anglo-saxônico, num parlamentarismo à feição do gênio latino. Então criou o Presidente com poderes parecidos com os poderes do Presiden- te dos EUA, mas deu a ele o direito, inclusive, de dissolver o Congresso.

Aqui no Brasil, no momento, se pretende resolver uma crise política com um parlamentarismo de conveniência já vai descaracterizado na hora em que ele for posto em vigor, mas se inventa o neoparlamentarismo, que o Prof. João Gilberto criticou aqui muitíssimo bem, com a correção que todos nós nos habituamos a vê-lo discutir as matérias. Inventa-se um parlamentarismo em que o Presidente da República pode fazer isso, aquilo outro, mas não pode dissolver a Câmara.

Ora, se justamente a característica fundamental do parlamentarismo estả neste equilíbrio. Os políticos podem derrubar o governo, derrubando o Primeiro-Ministro e o Presidente pode derrubar os políticos e se retira uma destas duas bases fundamentais das pernas de sustentação do parlamentarismo, nós não temos parlamentarismo. Então o que se está inventando no Brasil hoje são misturas cada vez mais ridiculas de sistema presidencialista com sistema parlamentarista.

Eu ficaria, portanto, com esta colocação mais próxima de uma situação real e efetiva, que é esta lembrada pelo Ministro Nascimento Silva. Um presidencialismo que não dê ao Presidente da República no Brasil o poder de um César Romano. O artigo 16 da Constituição francesa permite a disposição de um César Romano. Mas acontece que ele foi usado em determinado momento e não mais. $\mathrm{E}$ aqui nós temos ainda um Presidente com capacidade de fazer decretos-lei à vontade, embora na campanha eleitoral se declare que não se fará mais, mas assume-se o poder, faz-se mais do que antes, e se aí há a ação de um Presidente da República que pode fazer vetos, e tem esses vetos com extrema dificuldade discutidos e derrubados no Congresso, então é preciso dar força ao Congresso.

Dando-se "força ao Congresso, retirando-se parte desse excesso de poder dado ao Executivo, eu acredito que seria um caminho mais eficaz para 0 Brasil, e concluo isto a partir exatamente da análise, da minha análise crítica a respeito das duas conferências e da exposição feita. 